summer water-column structure depends on the heat loss from the region during the preceding ice season, the amount of ice over the basin, and the total amount of ice formation in the Okhotsk Sea. During the heavy ice year of 1979 , the upper $200-300 \mathrm{~m}$ were cooler, less saline, and highly oxygenated. This modification appears to be a local process, driven by eddy-induced mixing, local cooling, and ice melting. At $300-1200 \mathrm{~m}$ depths, water modification is caused by advection of water from outside the Kuril Basin. During heavy ice years with strong cooling, this water is more saline, colder, and richer in oxygen than during lighter ice years. The water modified in the basin can be traced into the North Pacific, where it cools and dilutes the surface water, and oxygenates the upper $200-400 \mathrm{~m}$.

\title{
INCREASED ACCUMULATION ON THE ANTARCTIC ICE SHEET DUE TO CLIMATIC WARMING
}

\author{
(Abstract)
}

by

Stephen Warren*

(Glaciology Section, Antarctic Division, Earth Sciences School, University of Melbourne, Parkville, Victoria 3052, Australia)

and

Susan Frankenstein

(Oceanography Department, University of Washington, Seattle, WA 98195, U.S.A.)

Climatic warming due to increased greenhouse gases is expected to cause increased precipitation in the next century because of the increased water content of the air, assuming constant relative humidity. Since temperatures over most of Antarctica are far below freezing even in the warmest month of the year, the increase in melting is probably negligible compared to the increase in precipitation.

Oerlemans (1982) showed that this increase of precipitation would cause a growth of the ice sheet, tending to lower sea level. This would partially counteract the rise of sea level due to increased melting on mountain glaciers and Greenland, and to a possible (and more difficult to predict) surge of ice from West Antarctica.

Oerlemans may have underestimated the increase in accumulation. He used results of General Circulation Models (GCMs) which indicated an increase of precipitation by only $12 \%$ for a temperature change $\Delta \mathrm{T}=3 \mathrm{~K}$ and $30 \%$ for $\Delta \mathrm{T}=$ $8 \mathrm{~K}$. In contrast, the change in accumulation rate at Dome C (Lorius and others, 1979) accompanying the warming from the recent ice age to the present was in accord with the simple assumption that accumulation is proportional to saturation vapor pressure at the temperature of the inversion layer, i.e. a $30 \%$ increase for $\Delta \mathrm{T}=3 \mathrm{~K}$.

The experimental results are to be preferred to the climate model results because GCMs do not represent icesheet accumulation processes well. Most of the accumulation is not snow falling from clouds but instead results from clear-sky ice-crystal formation in near-surface air, or hoarfrost deposition on the surface. GCMs lack sufficient vertical resolution to represent the strong temperature inversion on which these accumulation mechanisms depend.

The figure shows that the increase of vapor pressure due to $\Delta \mathrm{T}=5 \mathrm{~K}$ varies from a factor of 1.9 at $\mathrm{T}=-60^{\circ} \mathrm{C}$ to a factor of 1.6 at $\mathrm{T}=-20^{\circ} \mathrm{C}$. A climatic warming of $5 \mathrm{~K}$ over Antarctica, which is possible during the next century, could thus increase the Antarctic accumulation from its present $17 \mathrm{~g} \mathrm{~cm}^{-2} \mathrm{yr}^{-1}$ to $30 \mathrm{~g} \mathrm{~cm}^{-2} \mathrm{yr}^{-1}$, leading to a

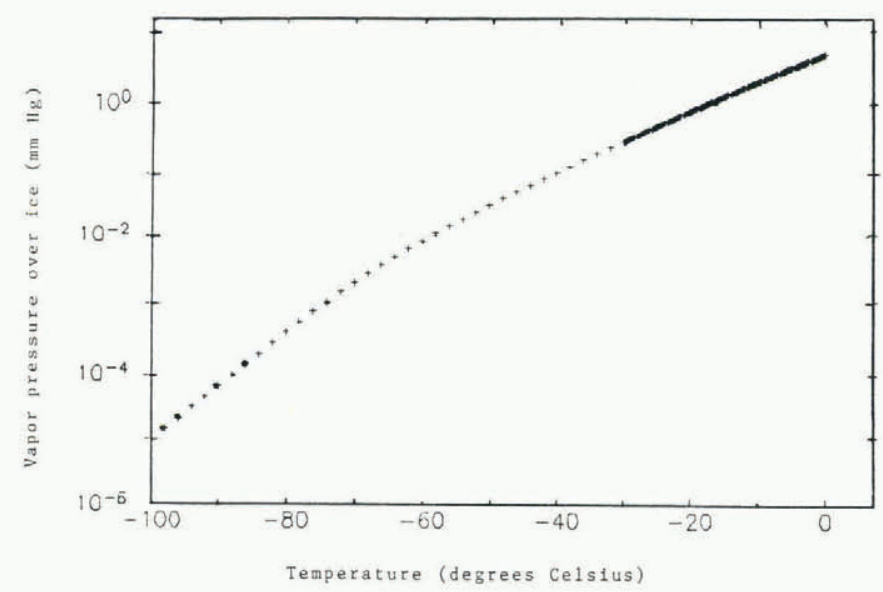

$50 \mathrm{~cm}$ drop in sea level in 100 years. This assumes that the simple proportionality of precipitation rate to saturation vapor pressure applies as well to the coastal regions, which is doubtful because the accumulation processes are not the same as on the plateau.

The potential importance of Antarctic accumulation changes in contributing to changes of sea level argues for further study of the mechanisms of Antarctic precipitation and for their improved representation in climate models.

\section{REFERENCES}

Lorius, C., L. Merlivat, J. Jouzel, and M. Pourchet. 1979. A $30000-y r$ isotope climatic record from Antarctic ice. Nature, 280, 644-648.

Oerlemans, J. 1982. Response of the Antarctic ice sheet to a climatic warming: a model study. J. Climatol., 2, 1-11.

* current address: Atmospheric Sciences, AK40, University of Washington, Seattle, WA 98195, U.S.A. 